\title{
UM CLÁSSICO DA MODERNIDADE CLÁSSICA: ALFRED DÖBLIN E SUA CONSTRUÇÃO POETOLÓGICA
}

Rafael Humberto Silveira*

RESUMO: O presente artigo procura estabelecer uma relação entre a concepção poetológica de Alfred Döblin e o contexto histórico e cultural no qual o autor a desenvolveu, ressaltando os aspectos vanguardísticos de renovação literária estrutural propostos pelo mesmo.

PALAVRAS-CHAVE: literatura alemã; Alfred Döblin; Modernidade clássica; vanguarda literária europeia.
* rafaeljena@gmail.com

Ex-aluno de Letras da UFMG, mestrando em LiteraturKunst-Kultur na Universidade Friedrich Schiller de Jena, Alemanha, formado em Germanistica em 2012 universidade.

ABSTRACT: The aim of this article is to relate Alfred Döblin's poetological conception and the historical context in which it was developed, focusing on the experimental aspects of structural literary renewal presented by the author.

KEYWORDS: german literature; Alfred Döblin; classical modernity; european literary avant-garde. 
1. Todas as traduções que se seguem são de minha autoria. Títulos de obras inéditas em língua portuguesa foram traduzidos da forma mais próxima possível do original.

2. MARINETTI. "Manifesto Técnico" da Literatura Futurista (11 de maio de 1912), p. 81 sq. V. ainda dentre outros esp. SALARIS. Futurismo: l'avanguardia delle avanguardie.

3. DÖBLIN. Futuristische Worttechnik. Offener Brief an F. T. Marinetti, p. 536-7.
Há exatamente cem anos (portanto em 1913) Alfred Döblin publicava na revista alemã Der Sturm dois ensaios de grande importância para os estudos literários modernos: Primeiramente "Técnica futurista de palavras. Carta aberta a F. T. Marinetti" ("Futuristische Worttechnik. Offener Brief an F. T. Marinetti"), ${ }^{1}$ em que o autor critica o Futurismo italiano e a radicalidade de seu principal representante, cujo manifesto de 1909 declarava: "Nós queremos destruir os museus, as bibliotecas, as academias de toda natureza, e combater o moralismo, o feminismo e toda vileza oportunista

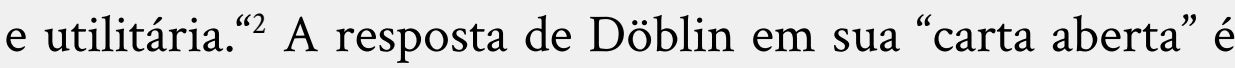
igualmente exaltada:

Nós nos alegramos com todo estilo original e enérgico; no desejo ardente por realidade somos camaradas; - mas nem por isso venha com decretos categoriais a nós, que sabemos tudo tão bem, muito até melhor que o senhor, por isso sem gesto de estremecer o mundo ou expressões homicidas. [...] Marinetti, o senhor nos ataca; nos insulta de passadistas e retrógrados; não apenas defendo minha literatura, como também ataco a sua. ${ }^{3}$

E em seguida, no mesmo ano e no mesmo veículo de publicação, surge "A romancistas e seus críticos. Programa berlinense", em que o autor, sem se vincular a nenhuma corrente literária, reformula estímulos vanguardistas não em favor de uma tendência estética específica, mas sim em prol de um estilo mais dinâmico e portanto mais atual e condizente com a velocidade da vida nas grandes cidades: "A representação exige, em face da enorme quantidade de formações, um estilo cinematográfico. [...] A história não é contada, ela é construída. [...] Sequências rápidas, caos em termos soltos [...] O todo não deve aparecer como enunciado, mas sim como existente". ${ }^{4}$ A metaforização da construção discursiva elaborada por Döblin neste ensaio se comunica com outras vanguardas artísticas da época, como, por exemplo, com o Construtivismo do artista e arquiteto russo El Lissitzky, que formula suas pretensões criativas de forma similar ao Programa berlinense: "Meu objetivo [...] não é representar, mas antes criar algo autonomamente existente".

Isso mostra que, embora relativamente curtas em sua extensão, essas duas veementes expressões poetológicas de Döblin representam bem as tensões que marcaram o período a ser analisado no presente artigo. Os anos de aproximadamente 1880 até 1933 caracterizaram-se, em diversas esferas sociais, por uma ruptura, por vezes radical, com a tradição. Na Europa, essa ruptura se tornou particularmente evidente na pluralização e polarização de tendências vanguardistas artísticas e técnicas, conhecidas sob o nome de 'ismos' da virada do século. No entanto, apesar da grande tensão entre eles e embora muitas vezes antagônicos em
4. DÖBLIN. An Romanautoren und ihre Kritiker. Berliner Programm, p. 542.

5. SIMONS. EI Lissitzky Proun $23 N$. Der Umstieg von der Malerei zur Gestaltung, p. 26.

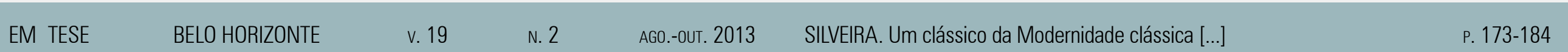

\section{Crítica Literária, outras Artes e Midias}


6. KIMMICH / WILKE. Einführung in die Literatur der Jahrhundertwende, p. 19.

7. Cf. o Dicionário Houaiss da língua portuguesa.

8. Aqui e no que imediatamente se segue me baseio em VENTURELLI. Robert Musil und die ldee einer "klassischen
Moderne". suas premissas, os 'ismos' possuem mais em comum do que apenas sua sufixação. Eles se desenvolvem no processo da "Segunda Revolução Industrial", 6 em que a consolidação de grandes centros urbanos, como Paris, Berlim e Viena catalizou a sensação generalizada de se poder cada vez menos considerar atuais ou 'modernos' (da etimologia latina de modernus para 'atual, recente, contemporâneo') ${ }^{7}$ os padrões e valores que até então haviam norteado a vida. Com base no trecho do manifesto futurista e da carta aberta de Döblin a Marinetti, citados acima, é possível perceber que o passado - e com ele a tradição no sentido da transmissão de valores e padrões - assume a negatividade conotativa de um insulto, sendo associada à obsolência que justificaria sua destruição. O surgimento de uma tal postura está relacionado com o fato de que o conservadorismo e a tradição perderam seu valor ao deixarem de ser capazes de fornecer respostas adequadas para novos problemas, uma vez que a velocidade das inovações tecnológicas e das transformações sociais aumentou consideravelmente a partir das últimas décadas do século XIX, período em que começa a se desenvolver o conceito de modernidade que culminaria no período hoje convencionalmente identificado, especialmente nas Ciências Sociais, por "Modernidade clássica".

O caráter paradoxal deste termo, que teria sido cunhado no início dos anos 2000 pelo Fórum da Sociedade Internaciona
Robert Musil (Musil-Forum der Internationalen RobertMusil-Gesellschaft) na série de "estudos da literatura da Modernidade clássica", 9 advém não apenas da aparente contradição entre o conceito de 'clássico' como tradicional, canônico, consolidado e de 'moderno' como ruptura, inovação, atualização, ${ }^{10}$ mas também da ideia de que a Modernidade clássica seria o período de culminação e consolidação de paradigmas artísticos e culturais de uma época caracterizada exatamente pela ruptura de paradigmas. No entanto, a proximidade do termo de um oxímoro possui um caráter de aproximação formal em relação ao objeto, como se o defi niendum imitasse o definiens em sua complexidade. Por se tratar de um campo ainda em construção através do debate científico, sua transposição para um panorama linguístico e cultural além dos países de língua alemã, embora imprescindível, traz consigo ainda mais dificuldades, sobretudo pela generalizada falta de consistência e de critérios definitórios já no concernente ao inflacionado emprego do termo 'Modernidade'. Ao contrário de ter a pretensão de buscar uma solução para a quadratura desse círculo, ${ }^{11}$ ou seja, uma definição completa e categórica do conceito de Modernidade clássica para os estudos literários, o presente artigo é, antes de mais nada, uma tentativa de apresentar e trabalhar com a indefinição deste e do próprio conceito de Modernidade em busca de um objetivo primário bem mais acessível: esboçar os contornos da arquitetura poetológica de um autor
9. V. o site da Robert-MusilGesellschaft em (http://www. musilgesellschaft.at/musilforum. $\mathrm{htm})$ para atualizações.

10. V. BROCK. Die klassische Moderne. Moderne Gesel/schaften, p. 17.

11. Também em alusão a questionamentos semelhantes em SANNA. Die Quadratur des Kreises: Stadt und Wahnsinn in "Berlin Alexanderplatz" von Alfred Döblin, 2000.

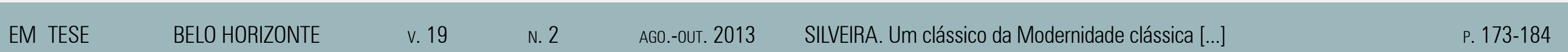

\section{Crítica Literária, outras Artes e Midias}


12. Sobre a Modernidade clássica, V., além de VENTURELLI. Robert Musil und die Idee einer "klassischen Moderne" e BROCK. Die klassische Moderne. Moderne Gesellschaften; e ainda BECKER. Klassische versus avantgardistische Moderne: Alfred Döblin zwischen Tradition und Inovation, p. 1-14. Sobre a Modernidade literária, $v$. esp. KIESEL. Geschichte der literarischen Moderne. Sprache, Ästhetik, Dichtung im zwanzigsten Jahrhundert assim como BECKER / KIESEL (orgs.). Literarische Moderne: Begriff und Phänomen

13. VENTURELLI. Robert Musil und die Idee einer "klassischen Moderne", p. 18 que pode ser considerado um 'clássico' moderno, dentro dos principais critérios da Modernidade clássica, que serão apresentados no que se segue. ${ }^{12}$

As características fundamentais da Modernidade clássica, ressaltadas por Aldo Venturelli em vinculação a Matthias Luserke-Jaqui e Rosemarie Zeller, são "a renúncia ao rigor narrativo, a progressiva perda do eu, a impossibilidade de abarcar, por meio do romance, a crescente complexidade do mundo e a polivalência fugaz da Modernidade, assim como o questionamento de toda norma rigidamente definida." ${ }^{13}$ Com o auxílio de alguns exemplos, quero mostrar o quanto essas propriedades estão presentes no discurso poetológico e na obra de Alfred Döblin.

Começando pela última das características da Modernidade clássica acima elencadas, é possível encontrar afirmações claras nos escritos poetológicos de Döblin que coadunam plenamente com a ideia do questionamento da norma estética estabelecida. Ao final de sua carta aberta de 1913, o autor pede a Marinetti que nunca se esqueça "que não há arte, apenas artistas" e encerra com a célebre frase: "Cuide do seu Futurismo. Eu cuido do meu Döblinismo”. Esse enfoque na individualidade e na autonomia criativa do artista e, consequentemente, em sua libertação de categorias estilísticas e dogmas criativos perpassa da mesma forma o ensaio, escrito em 1929 (ou seja, logo após a erupção criativa de Berlin Alexanderplatz) "A arte não é livre, mas sim efetiva: ars militans" em que Döblin afirma que "[o] artista tem que criar sua própria liberdade" ${ }^{14}$ e enfantiza essa libertação com o apelo: "Quero reiteradamente conclamar os autores a não servirem à forma, mas sim a servirem-se da forma". Considerando-se tais afirmações fica evidente que a dificuldade de se categorizar a obra de Döblin advém também da postura libertária do autor, que nunca se limitou a seguir uma tendência literária única e permeou - por vezes até mes mo dentro de uma mesma obra - diferentes estilos poéticos.

A própria renovação da escrita no sentido de sua adaptação à realidade moderna, outra característica da Modernidade clássica citada por Venturelli, parte também da experiência individual do autor em seu tumultuado cotidiano numa igualmente tumultuada metrópole - Berlim, uma das maiores cidades do mundo nas primeiras décadas do século XX. ${ }^{16}$ Após sua diplomação como médico neurologista especializado em psiquiatria em 1905 na universidade de Freiburg im Breisgau, Döblin retorna para Berlim, onde trabalha como médico assistente. ${ }^{17} \mathrm{O}$ contato com Herwarth Walden, ativo incentivador das vanguardas, lhe possibilita a publicação, em 1908, de seu primeiro conto, "Das Stiftsfräulein und der Tod”, escrito ainda em Freiburg, na revista Das Magazin. Dividindo seu tempo entre a psiquiatria e a literatura, Döblin segue colaborando com o amigo Walden na revista
14. DÖBLIN. Kunst ist nicht frei, sondern wirksam: ars militans, p. 103.

15. Ibid., p. 115.

EM TESE BELO HORIZONTE $\quad$ v. $19 \quad$ N. $2 \quad$ AG0.-0ut. $2013 \quad$ SILVElRA. Um clássico da Modernidade clássica [...] $\quad$ P. 173-184

\section{Crítica Literária, outras Artes e Mídias}


Der Sturm, publicada por este de 1910 a 1932, com contos e ensaios como os anteriormente citados, além de manter contato com nomes importantes da vanguarda artística como Ernst Ludwig Kirchner, Gottfried Benn e Else LaskerSchüler. A desafiliação do judaismo, o casamento com Erna Reiss em 1912, o nascimento de dois filhos (um já em 1911, fruto de um caso amoroso com a enfermeira Frieda Kunke) e as respectivas dificuldades financeiras obrigaram Döblin a um maior comprometimento profissional com a medicina, porém não conseguiram separá-lo da atividade literária: "Quando me vinha o 'ímpeto', eu tinha um pedaço de papel comigo e um lápis, rabiscava no ônibus, de madrugada no pronto-socorro ou à noite em casa". ${ }^{18} \mathrm{O}$ cotidiano agitado, as tensões pessoais, políticas e sociais, além do contato com as classes mais baixas da grande cidade marcam a obra do autor, ainda que nem sempre à primeira vista, em seus romances situados em épocas - como o épico histórico Wallenstein ou lugares longínquos - como a China em Die drei Sprünge des Wang-lun. Döblin escreve sobre isso em seu ensaio de 1938 "O romance histórico e nós": "[...] é sem dúvida possível ir ao Egito, à Espanha ou aonde quer que seja e contar os acontecimentos do ano 1550, de 1200 ou até 3000 antes de Cristo e ainda assim reportar sobre a atual atualidade, assim os políticos não escutam". Nesse sentido, seu conceito de "fantasia factual" (Tatsachenphantasie), apresentado no "Programa berlinense", representa, na verdade, um desafio para as formas de categorização literária, circunstância que pode ser exemplificada através da análise do conto "As duas amigas e seu envenenamento" ("Die beiden Freundinnen und ihr Giftmord”). Em 1923, dez anos após a publicação do "Programa berlinense", Döblin é convidado pelo escritor expressionista Rudolf Leonhard a inaugurar a série de publicações intitulada "Marginais da sociedade. Os criminosos do presente" ("Außenseiter der Gesellschaft. Die Verbrecher der Gegenwart") com o referido conto: uma elaboração minuciosa e detalhada do processo de um dos maiores escândalos criminais da época - o caso Klein / Nebbe. A história de Elli Klein, que envenenou seu marido com a ajuda da amiga (e, em seguida, amante) Margarete Nebbe, é reconstruída por Döblin sem grandes artifícios narrativos, com um estilo rigoroso, preciso e conciso, praticamente 'documentário'. No entanto, fica evidente a tentativa de explicitar o percurso psicológico da figura principal através de detalhadas descrições de seus estados emocionais e suas relações afetivas, que se tornam cada vez mais doentias. Ao final do conto Döblin escreve um epílogo no qual comenta sua intenção com o relato e questiona a opinião pública, que julgara a pena para Elli Klein pouco severa. Para seus estudos preparatórios o autor consegue acesso ao diário de Elli Klein, usado como prova nas investigações, e a atas do processo de acusação através do advogado Dr. Lamm. Embora altere os nomes de família dos principais envolvidos no caso, Döblin reproduz

$\begin{array}{llllll}\text { EM TESE } & \text { BELO HORIZONTE } & \text { v. } 19 & \text { N. } 2 & \text { AG0.-0ut. } 2013 & \text { SILVEIRA. Um clássico da Modernidade clássica [...] }\end{array}$

\section{Crítica Literária, outras Artes e Mídias}


fielmente a biografia dos mesmos e a versão apresentada nos autos, chegando a copiar ou parafrasear trechos e a citar localidades e horários verídicos. A focalização narrativa alterna o discursos direto, indireto e indireto livre completamente em função do que é relatado, ou seja, a instância narrativa se coloca atrás dos fatos apresentados como um repórter, gerando uma espécie de 'colcha de retalhos discursiva'.

Essa quebra com o rigor narrativo em "As duas amigas e seu envenenamento" pode ser interpretada sob a perspectiva da busca da "despersonalização" do autor em função da matéria representada. A técnica, postulada já no "Programa berlinense" e testada neste conto, é aprimorada e intensificada em Berlin Alexanderplatz, em que o autor reproduz diversos trechos de documentos, horários de transportes públicos, previsões do tempo, discursos políticos, resultados de disputas esportivas, comunicados oficiais, etc. Döblin comenta sua fascinação pela factualidade em seu ensaio de 1928, "A construção da obra épica” (“Der Bau des epischen Werks”):

Eu mesmo confesso: idolatrei ardentemente a reportagem, o dogma da cortina de ferro. Nada me parecia mais importante que a chamada objetividade do narrador. Eu admito que ainda hoje a comunicação de fatos, de documentos me faz feliz, mas documentos, fatos, sabe por que? Assim o grande poeta épico a natureza, fala a mim, e eu, pequeno, paro e me alegro de ver como meu irmão mais velho sabe fazer. E foi isso que senti ao escrever este ou outro livro histórico, que eu mal podia me conter em copiar atas inteiras por completo, eu me afundava por vezes nas atas, maravilhado, dizendo: não consigo mesmo fazer melhor. ${ }^{19}$

O enfoque dessa característica, típica da corrente literária alemã 'Nova objetividade' ('Neue Sachlichkeit'), eventualmente deu margem à categorização de "As duas amigas e seu envenenamento" como pertencente a este contexto estilístico. ${ }^{20}$ No entanto, contemplando-se o conjunto da obra de Döblin, fica evidente que a despersonalização é antes um traço de seu "Döblinismo" que de uma espécie de realismo social, já que o autor não desenvolveu um programa e nem mesmo escreveu nenhuma obra que pudessem, em sua totalidade, ser categorizados como pertencente à Nova objetividade. A tendência documental de sua escrita está muito mais próxima de um engajamento social e de uma preocupação com o ativismo da arte ("ars militans") que de uma opção estetico-estilística, como mostra o seguinte trecho de seu "Programa berlinense":

Afirmo que todo bom especulador, banqueiro, soldado é melhor poeta que a maioria dos autores atuais. [...] É preciso controlar as necessidade supostamente interiores e agarrar as
19. DÖBLIN. Der Bau des epischen Werks, p. 579-80.

20. Como p. ex. em Sander. Alfred Döblin, p. 167.

\section{Crítica Literária, outras Artes e Mídias}


21. Döblin. An Romanautoren und ihre Kritiker. Berliner Programm, p. 540 .

22. Aqui e no que se segue me oriento por Sander. Alfred Döblin, p. 42 e 252-6. rédeas da arte. Escrever não é roer unha ou palitar os dentes, mas sim uma questão pública. ${ }^{21}$

Uma outra questão pública defendida por Döblin é a luta contra a proliferação, cada vez mais flagrante, de tendências políticas reacionárias na República de Weimar. A seu lado estavam nomes ilustres como Bertolt Brecht, Walter Mehring, Ernst Bloch, Ernst Toller, Käthe Kollwitz, membros do "Grupo 1925", dentre outros. ${ }^{22}$ Seu ativismo socia se manifesta especialmente em sua obra, que não raro contempla figuras situadas à margem da sociedade - como no caso da tematização do caso homoerótico de "As duas amigas e seu envenenamento".

A progressiva perda do eu, outra das características principais da Modernidade clássica segundo Luserke-Jaqui e Zeller, se manifesta neste conto na sublimação da instância narrativa, ou seja, na modulação e redução da intervenção de um narrador sobre a diegese. Também em função disso o conto pode ser considerar uma preparação para a maximização da estratégia poética da despersonalização em Berlin Alexanderplatz. A despersonalização se aproxima do estilo que o americano John dos Passos utiliza em seu romance Manhattan Transfer, de 1925, em que aproximadamente uma centena de histórias, não necessariamente relacionadas entre si, são iniciadas e abandonadas sem necessariamente terem se concluído. O estilo de dos Passos - filho ilegítimo de um imigrante português bem sucedido nos E.U.A. -, enquadrado na "geração perdida" ${ }^{23}$ de Hemingway, Fitzgerald e Eliot, tornou-se mundialmente famoso. Sua estratégia narrativa foi chamada ainda de "camera eye", em associação a uma câmera cinematográfica que se move pela cidade, aproximando-se, acompanhando e abandonando as diversas personagens e seus destinos. Independentemente de Döblin ter de fato se inspirado ou não em dos Passos, como já foi discutido em diversos debates literários, Berlin Alexanderplatz e Manhattan Transfer apresentam passagens muito similares em relação à instância narrativa que se omite e deixa a história ser como que 'contada pelos próprios fatos'.

Também Döblin começa a se tornar conhecido a partir de 1925 em razão de uma série de contribuições suas para o programa de rádio "Berliner Funkstunde". ${ }^{24}$ Em função dessa experiência e do sucesso de seu livro Berlin Alexanderplatz. A história de Franz Biberkopf, ele viria a ser convidado pela Academia Prussiana de Artes (Preußische Akademie der Künste) em setembro de 1929 para uma palestra inaugural de uma conferência sobre literatura e radiodifusão na cidade de Kassel que reuniu importantes nomes da cena literária e cultural da época, como Walter Molo, Ernst Hardt, Hermann Kasack, Arnold Zweig, Arnolt Bronnen, dentre outros. Provavelmente em 1930 Döblin, embora com complicações de saúde, começa a trabalhar na versão de
23. KLOTZ Nachwort zu Manhattan Transfer, p. 433-446.
24. A radiodifusão se propaga extremamente rápido nos anos de 1920 em Berlim. A história da torre de radiodifusão de Berlim (Berliner Funkturm), construíd para a Feira Internacional de Radiodifusão (Internationale Funkausstellung) de 1925 e hoje transformada num ponto turístico, documenta exemplarmente esse fascinante e célere processo tanto impulsionado quanto interrompido por duas guerras mundiais.

EM TESE $\quad$ BELO HORIZONTE $\quad$ v. $19 \quad$ N. $2 \quad$ AG0.-0ut. $2013 \quad$ SILVElRA. Um clássico da Modernidade clássica [...] $\quad$ P. 173-184

\section{Crítica Literária, outras Artes e Mídias}


25. DÖBLIN. Die Geschichte vom Franz Biberkopf (Funktyposkript des Hörspiels), p. 297.
Berlin Alexanderplatz para o rádio, intitulada apenas "A história de Franz Biberkopf”. A redução do título revela uma redução da própria trama, que gira, nessa versão, em torno da personagem principal, deixando a representação da metrópole e seu ritmo acelerado antes como pano de fundo incidental. Na peça radiofônica, finalizada por Döblin antes do início da primeira adaptação cinematográfica, a construção do contexto cênico, tão presente no romance, é mantida em segundo plano, estimulada auditivamente por um bulício multitudinário indistinto, deixando a nitidez do cenário quase que completamente a cargo da capacidade imaginativa do ouvinte. $\mathrm{O}$ único elemento a situar geograficamente a ação é o dialeto de Berlim, que dá vida ao humor sarcástico característico da prosa döbliniana. Além disso, a mise-en-scène é expandida nas mais variadas associações (como a temática da guerra e das tensões políticas do período) por meio de uma trilha sonora incidental, instrumental e musical. Um exemplo é a introdução da marcha militar "Wenn die Soldaten durch die Stadt marschieren" ("Quando os soldados marcham pela cidade”) na cena em que Franz, já após ter perdido o braço direito, decide ir ao encontro de Reinhold. ${ }^{25}$ Uma parte da canção é repetida na peça pelas duas personagens ao se encontrarem, numa alusão aos diversos motivos temáticos que se repetem ao longo do livro. A polifonia narrativa do romance (como nos fluxos de consciência de Franz Biberkopf, geralmente representados através do discurso indireto livre) é parcialmente reconstruída no rádio através da adoção de diferentes papéis pelas mesmas vozes em diferentes contextos. O problema da fixação de uma determinada figura a um papel narrativo é por vezes resolvido de forma extremamente simples, nomeando-se o papel no roteiro apenas como "voz" ou como "narrador" e possibilitando-se, assim, sua camuflagem em meio à multidão da polifonia narrativa:

Meck: 'cê 'tá bem robusto, né, seu peso pesado, vai botar a casa abaixo. Franz: É, eu acho.

Voz: Não sei não.

Narrador: Quem disse não sei não[?]

Voz: Não sei não. ${ }^{26}$

Uma solução, em relação a esse aspecto, aparentemente mais efetiva que a das adaptações fílmicas de Phil Jutzi, em 1931 e de Rainer Werner Fassbinder em 1980 - obras de valor artístico inquestionável, cuja análise mais profunda terá, no entanto, de ser aqui postergada para uma outra oportunidade. É possível salientar de forma resumida, entretanto, que a "escrita fílmica" ("filmische Schreibweise"), atribuída ao romance Berlin Alexanderplatz, parece, no que concerne suas adaptações fílmicas, antes ter gerado imensas expectativas e dificuldades de realização que estimulado potencialidades e possibilidades de poíesis e tékhne. ${ }^{27} \mathrm{O}$ principal motivo para tanto pode ser atribuído ao fato de que na Modernidade,
26. Ibid., p. 276.

27. HURST. Erzäh/situationen in Literatur und Film: ein Modell zur vergleichenden Analyse von filmischen Adaptionen und filmischen Adaptionen, p. 264. Hurst argumenta que o principio da montagem no romance levaria à destrução do narrador autorial e por conseguinte à negação da situação narrativa. A "escrita filmica do romáce seria mais fílmica que o próprio filme, culminando numa escrita "ultracinematográfica" (p. 262).
EM TESE BELO HORIZONTE $\quad$ v. $19 \quad$ N. $2 \quad$ AG0.-0ut. $2013 \quad$ SILVElRA. Um clássico da Modernidade clássica [...] $\quad$ P. 173-184

Crítica Literária, outras Artes e Mídias 
muito mais do que em outras épocas, parte considerável do conteúdo de uma obra de arte advém de sua forma. A separação da trama de Berlin Alexanderplatz da forma como ela é comunicada no romance implica perda de parte do conteúdo da obra, uma parte que não é comunicada através da língua, mas sim da linguagem. Como transpor diretamente para uma peça radiofônica, por exemplo, os símbolos de órgãos municipais da cidade de Berlim, apresentados no início do segundo livro do romance döbliniano? É possível reconstruir com mínima clareza as conotações sociais de um dialeto, como o berlinense, em uma tradução? São questões que perpassam épicos da literatura mundial moderna, como Berlin Alexanderplatz, Finnegans Wake (1939) de James Joyce e Grande Sertão, Veredas (1956) de Guimarães Rosa, que extrapolam largamente a "linguagem de em dia-de-semana". ${ }^{28}$ Esse é talvez o maior desafio das traduções linguísticas e midiáticas na Modernidade: a reconstrução não apenas do sentido total da obra - por vezes sintetizável em poucas linhas -, mas também da parte deste sentido que advém da relação significante - significado, uma vez que outros significantes trazem consigo, invariavelmente, também outros significados.

Essa impossibilidade de exaurir a essência da obra de arte em sua profundidade e ambiguidades está relacionada a outra das características da Modernidade clássica, apresentadas

EM TESE no início da presente análise: "a impossibilidade de abarcar, por meio do romance, a crescente complexidade do mundo e a polivalência fugaz da Modernidade”. ${ }^{29}$ A obra de Döblin espelha o contexto em que o autor viveu, permitindo afirmar que ele se manteve fiel não a uma tendência ou escola artística, mas sim a si mesmo. Essa propriedade é talvez o fator principal que permite sua categorização como 'clássico' da Modernidade clássica e como exemplo paradigmático da vanguarda intelectual europeia do início do século XX. Paradoxalmente, essa posição não contradiz a opinião de Günter Grass em seu discurso de 1967 "Sobre meu professor Döblin” ("Über meinen Lehrer Döblin”), na Academia das Artes de Berlim (Akademie der Künste Berlin) por ocasião dos dez anos do falecimento do autor, em que Grass o classifica exatamente como "anti-clássico" ${ }^{30}$ Afinal, um clássico da Modernidade clássica - como período de ruptura e inovação - há de ser, nesse sentido, sobretudo anti-clássico. Apenas desta forma ele poderia sobreviver em meio à crise, não apenas do romance, como formulada por Walter Benjamin no ano de 1930 em referência a Berlin Alexanderplatz, ${ }^{31}$ como também à crise de sua própria estruturação biográfica em face da conjuntura política que a partir de 1933 sepulta definitivamente uma das épocas de maior efervescência criativa e intelectual da Modernidade. Fato que obriga Döblin, assim como o próprio Benjamin e ainda muitos outros, à imigração e a uma ruptura muito mais profunda e irreversível que
29. VENTURELLI. Robert Musil und die ldee einer "klassischen Moderne", p. 18

30. GRASS. Über meinen Lehrer Döblin, p. 11-34.

31. BENJAMIN. Krisis des Romans. Zu Döblins, Berlin Alexanderplatz".

\section{Crítica Literária, outras Artes e Mídias}


32. Como escreve Thomas Mann em seu diário em 7/11/1933. MANN. Tagebucheintrag v. 7.11.1933, p. 243 e também Klaus Mann em seu romance "O vulcão" (“Der Vulkan"): "Vocês estavam ocupados com seu próprio destino: o romance de suas vidas era suficientemente complicado e doloroso. As fronteiras que os separam da Alemanha são intransponíveis. Lá é uma região amaldiçoada para vocês; apenas em pesadelos são levados de volta a ela. Lá pessoas respiram, muitas delas sofrem, são expatriados na pátria, chamados de 'a emigração interna'". MANN. Der Vulkan, p. 539.

33. Como a morte de seu filho, o matemático Wolfgang Döblin (1915-1940), como soldado durante a luta pela França contra a Alemanha nazista.

34. BENJAMIN. Krisis des Romans. Zu Döblins „,Berlin Alexanderplatz", p. 562. qualquer outra até então colocada em prática: a ruptura com sua própria identidade, como artistas impedidos de criar, como refugiados impedidos de partir, como seres humanos proibidos de existir.

Um fim mais trágico para a Modernidade clássica é praticamente impensável. Embora tenha continuado a escrever Döblin, tal qual vários contemporâneos exilados no exterior, ou ainda como alguns em sua "migração interior", 32 passa a enfrentar severas dificuldades financeiras e pessoais ${ }^{33}$ que impedem ou suspendem o sentido de qualquer manifestação artística. O legado desse período, que constitui um marco na história das Artes, é outro dos principais critérios que ressaltam sua singularidade e embasam sua denominação como 'Modernidade clássica'. Afinal, falta àquilo que surgiu anteriormente e após esse período um certo caráter de urgência uma vitalidade criativa levada às últimas consequências, resumida pelas palavras de Benjamin ao se referir à escrita de Döblin:

A sala de parto do romance é o indivíduo em sua solidão, que já não sabe expressar seus interesses mais fundamentais de forma exemplar, estando ele próprio carente de conselho, não sendo capaz de aconselhar ninguém. Escrever um romance significa extremar o incomensurável na representação da existência humana. ${ }^{34}$

\section{REFERÊNCIAS}

AJOURI, Philip. Literatur um 1900. Naturalismus - Fin de Siècle - Expressionismus. Studienbuch Literaturwissenschaft. Berlim: Akademie Verlag, 2009.

BECKER, Sabine. Klassische versus avantgardistische Moderne: Alfred Döblin zwischen Tradition und Inovation. In: DUTT, Carsten; LUCKSCHEITER, Roman (orgs.): Figurationen der literarischen Moderne: Helmuth Kiesel zum 60. Geburtstag. Heidelberg: Winter, 2007, p. 1-14

BECKER, Sabine; KIESEL, Helmuth. Literarische Moderne: Begriff und Phänomen. Berlim [et al.]: de Gruyter, 2007.

BENJAMIN, Walter. Krisis des Romans. Zu Döblins „Berlin Alexanderplatz”. In: Die Gesellschaft. Bd. 1, 1930, p. 562-566.

BROCK, Ditmar. Die klassische Moderne. Moderne Gesellschaften. Erster Band. Wiesbaden: VS Verlag für Sozialwissenschaften / Springer Fachmedien, 2011.

CORNELSEN, Élcio L. O conceito de Kinostil e o princípio da montagem no romance Berlim Alexanderplatz, de Alfred Döblin In: Aletria. Revista de estudos de Literatura. V. 8. Literatura e cinema. Belo Horizonte: PosLit. FALE UFMG, 2001, p. 196-212.

Dicionário Houaiss da língua portuguesa. Rio de Janeiro: Ed. Objetiva, 2009

DÖBLIN, Alfred. Futuristische Worttechnik. Offener Brief an F. T. Marinetti. In: GRASS, Günter (org.). Alfred Döblin. Das Lesebuch. Frankfurt am Main: Fischer Verlag, 2012, p. 533-539.

\section{Crítica Literária, outras Artes e Mídias}


DOBLIN, Alfred. An Romanautoren und ihre Kritiker. Berliner Programm. In: GRASS, Günter (org.). Alfred Döblin. Das Lesebuch. Frankfurt am Main: Fischer Verlag, 2012, p. 540-543.

DÖBLIN, Alfred. Der Bau des epischen Werks. In: GRASS, Günter (org.). Alfred Döblin. Das Lesebuch. Frankfurt am Main: Fischer Verlag, 2012, p. 540-543.

DÖBLIN, Alfred. Die Geschichte vom Franz Biberkopf

(Funktyposkript des Hörspiels). In: KLEINSCHMIDT, Erich (org.):

Alfred Döblin: Drama, Hörspiel, Film Olten/Freiburg i. Br., 1983.

DÖBLIN, Alfred. Kunst ist nicht frei, sondern wirksam: ars militans. In: MUSCHG, Walter (org.): Ausgewählte Werke in Einzelbänden in Verbindung mit den Söhnen des Dichters Olten [et al.]: Walter-Verlag, 1963.

DÖBLIN, Alfred. Die Geschichte vom Franz Biberkopf: Hörspiel nach dem Roman Berlin Alexanderplatz. [peça radiofônica].

1931. Ed. por Heinz Schwitzke. Stuttgart: Reclam, 1976.

GRASS, Günter. Über meinen Lehrer Döblin. In: GRASS, Günter (org.). Alfred Döblin. Das Lesebuch. Frankfurt am Main: Fischer Verlag, 2012, p. 11-34.

HURST, Matthias. Erzählsituationen in Literatur und Film: ein Modell zur vergleichenden Analyse von literarischen Texten und filmischen Adaptionen. Tübingen: Niemeyer, 1996.

KIESEL, Helmuth. Geschichte der literarischen Moderne. Sprache, Ästhetik, Dichtung im zwanzigsten Jahrhundert München: C.H. Beck, 2004.
KIMMICH, Dorothee; WILKE, Tobias. Einführung in die Literatur der Jahrhundertwende. Darmstadt: WBG, 2011.

KLOTZ, Günther. Nachwort. In: DOS PASSOS, John: Manhattan Transfer. Weimar: Aufbau Verlag, 1986, p. 433-446.

MANN, Klaus. Der Vulkan. Roman unter Emigranten. Reinbek: Rowohlt, 1981.

MANN, Thomas. Tagebucheintrag v. 7.11.1933. In: JENS, Inge (org.). Tagebücher 1933-34. Frankfurt a. M., 1977, p. 243.

MARINETTI, Filippo Tommaso. "Manifesto Técnico" da Literatura Futurista (11 de maio de 1912). In: BERNARDINI, Aurora Fornoni (org.): O futurismo italiano - Manifestos. São Paulo: Perspectiva, 1980.

Robert-Musil-Gesellschaft. http://www.musilgesellschaft.at/ musilforum.htm Acesso em 20/07/2013.

ROSA, Guimarães. Famigerado. In: ROSA, Guimarães. Primeiras estórias. Rio de Janeiro: Nova Fronteira, 1988.

SALARIS, Claudia. Futurismo: I'avanguardia delle avanguardie. Firenze: Giunti, 2009.

SANDER, Gabriele. Alfred Döblin. Stuttgart: Reclam, 2001

SANNA, Simonetta. Die Quadratur des Kreises: Stadt und Wahnsinn in "Berlin Alexanderplatz" von Alfred Döblin. Frankfurt am Main: Lang, 2000 
SIMONS, Katrin. El Lissitzky Proun 23N. Der Umstieg von der

Malerei zur Gestaltung. Frankfurt a. M. e Leipzig: 1993.

VENTURELLI, Aldo. Robert Musil und die Idee einer "klassischen

Moderne". In: PONZI, Mauro (org.): Klassische Moderne. Ein

Paradigma des 20. Jahrhunderts. Würzburg: Königshaus und

Neumann, 2010, p. 17-33. Tradução do italiano para o alemão de

Leonie Schröder.

\section{Crítica Literária, outras Artes e Mídias}

